\title{
Cardiac overscreening hip fracture patients
}

\author{
S. J. M. Smeets ${ }^{1}\left[\right.$ - B. P. W. van Wunnik ${ }^{2} \cdot$ M. Poeze ${ }^{3} \cdot$ G. D. Slooter ${ }^{4}$ J. P. A. M. Verbruggen ${ }^{3}$
}

Received: 22 October 2018 / Published online: 31 August 2019

(c) The Author(s) 2019

\begin{abstract}
Background The aim of this study was to prospectively investigate the adherence to the American College of Cardiology (ACC) and the American Heart Association guidelines for perioperative assessment of patients with hip fracture in daily clinical practice and how this might affect outcome.

Methods This prospective cohort study from Maastricht University Medical Centre included 166 hip fracture patients within a 3-year inclusion period. The preoperative cardiac screening and adherence to the ACC/AHA guideline were analyzed. Cardiac risk was classified as low, intermediate and high risk. Secondary outcome measurements were delay to surgery, perioperative complications and in-hospital, 30-day, 1-year and 2-year mortality.

Results According to the ACC/AHA guideline, $87 \%$ of patients received correct preoperative cardiac screening. The most important reason for incorrect preoperative cardiac screening was overscreening $(>90 \%)$. Multivariate analysis showed that a cardiac consultation $(p=0.003)$ and overscreening $(p=0.02)$ as significant predictors for increased delay to surgery, while age, sex, previous cardiac history and preoperative mobility were not. High risk patients had in comparison with low risk patients a significantly higher relative risk ratio for in-hospital mortality (RR 6, 95\% CI 2-17). Multivariate analysis showed that a previous cardiac history and increased delay to surgery were predictors for early mortality. High age and previous cardiac history were risk factors for late mortality.

Conclusion Preoperative cardiac screening for hip fracture patients in adherence to the ACC/AHA guideline is associated with a diminished use of preoperative resources. Overscreening leads to greater delay to surgery, which poses a risk for perioperative complications and early mortality.

Level of evidence II.
\end{abstract}

Keywords Hip fracture $\cdot$ Cardiac screening $\cdot$ Preoperative screening $\cdot$ Geriatric $\cdot$ ACC/AHA guideline

\section{Introduction}

Hip fractures are one of the most common orthopaedic causes leading to hospital admission in the geriatric population and are associated with high morbidity and mortality rates [1]. All hip fracture patients receive preoperative

S. J. M. Smeets

ssmeets@flevoziekenhuis.nl

1 Department of Surgery, Flevoziekenhuis, Hospitaalweg 1, 1315 RA Almere, The Netherlands

2 Department of Surgery, Beatrixziekenhuis, Banneweg 57, 4204 AA Gorinchem, The Netherlands

3 Department of Surgery, Maastricht University Medical Centre, Maastricht, The Netherlands

4 Department of Surgery, Máxima Medical Center, De Run 4600, 5504 DB Veldhoven, The Netherlands screening for perioperative risk assessment, usually by the anesthesiologist. Preoperative screening includes often a preoperative cardiac consultation. The reason for this is not cardiac clearance, but cardiac risk assessment to determinate changes in perioperative patient management, including anesthesia, pharmacological and perioperative monitoring [2]. Preoperative cardiac consultation in patients with hip fractures is often time consuming and may lead to delay to surgery. Early operative treatment within $24-48 \mathrm{~h}$ is advocated to minimize the potential morbidity/mortality associated with delay to surgery [3-5]. Therefore, extended cardiac evaluation should be restricted if it is unlikely to change perioperative patient management [6-9].

According to the American College of Cardiology and the American Heart Association (ACC/AHA) guidelines hip surgery is considered intermediate risk surgery, due to the quantity of hemodynamic stress it induces [2]. This means 
that major ischemic cardiac complications occur in less than $5 \%$ of the time. However, the overall incidence of perioperative myocardial ischemia in elderly patients undergoing hip fracture surgery has been reported to be $22-53 \%$ [10, 11]. In addition, previous studies indicated that the principal causes of in-hospital death after hip fracture were cardiac failure and myocardial infarction, occurring early after the fracture $[12,13]$.

To reduce the risk of perioperative cardiac events the ACC/AHA have developed guidelines for preoperative risk stratification and cardiac assessment. The key points of these guidelines are summarized in an algorithm indicating the stepwise approach of patients using clinical predictors to identify their cardiac risk category.

In this study we prospectively evaluated whether the routine preoperative screening of hip fracture patients as performed in our department is in accordance with the ACC/ AHA guidelines and the consequences for daily practice in preoperative management and postoperative complications in a cohort of hip fracture patients.

\section{Materials and methods}

\section{Study population}

This prospective study was conducted in the Maastricht University Medical Centre in the Netherlands, a level 1 trauma center. All patients with a hip fracture admitted to the emergency department were eligible for inclusion. During a 3 -year period, patients of 65 years and above were included. After surgery there was a 2-year follow-up observation period or until death. Polytrauma patients, pathological hip fractures or patients with hip fractures who did not have surgery, were excluded. The department of trauma surgery and orthopaedic surgery used a protocolized treatment algorithm regarding hip replacement or internal fixation based on our National guidelines 'Proximal femur fractures', 2016 [14].

At admission the following score forms were recorded: the ASA (American Society of Anesthesiologists) score for physical status [15], the Barthel index for pre-injury functional evaluation [16], Metabolic Equivalent of Task
(MET) score for functional capacity [17], Mini Mental State Examination (MMSE) for cognitive impairment [18] and the Palmer and Parker score for mobility [19]. Furthermore, the preoperative cardiac work-up was described on the evaluation form using the ACC/AHA guideline template. Standard work-up after admission to the emergency room consisted of a detailed history, a complete physical examination, an electrocardiography and standard biochemical and hematologic tests. During preoperative screening the anesthesiologist decided whether a cardiac consultation was necessary. Extensive cardiac evaluation consisted of an evaluation of the patients performance state, medication review, assessment of the electrocardiogram, physical examination, an echocardiography on indication and advice was given regarding the cardiac risk in relation to the intended operation and recommendations on patient management in the perioperative period. The Maastricht Ethical committee approved the waiver of the requirement to obtain a signed consent form. All the questions and score forms were taken within the presence of a first-degree family member or sometimes legal representative in the case of dementia.

\section{Primary outcome measurements}

Our main goal was to evaluate the preoperative cardiac evaluation in daily practice, using the algorithm proposed in the ACC/AHA guideline. Clinical predictors for each risk group are shown in Table 1. 'Correctly screened' accounts for those patients who had surgery without cardiac consultation with a stable cardiac situation or in the absence of a cardiac history, or patients who received a cardiac consultation when indicated by the guideline. We defined two possibilities for preoperative cardiac screening that was not in line with the guidelines. 'Underscreening' was defined as a cardiac consultation that was indicated by the guidelines, but not executed. In other terms: preoperative cardiac screening that fell short. 'Overscreening' was defined as a cardiac consultation that was not indicated by the guideline, but still performed. In other terms, preoperative cardiac screening that was too extensive. Subsequently, the primary investigator (SM) analyzed the content of the preoperative cardiac consultations in relation to the patient's medical condition and discussed
Table 1 The American College of Cardiology/American Heart Association clinical predictors for each risk group

\begin{tabular}{lll}
\hline Low risk & Intermediate risk & High risk \\
\hline Advanced age & Mild angina pectoris & Unstable coronary syndromes \\
Abnormal ECG & $\begin{array}{l}\text { Prior myocardial infarction } \\
\text { Rhythm other than sinus }\end{array}$ & $\begin{array}{l}\text { Decompensated cardiac heart failure } \\
\text { heart failure }\end{array}$ \\
$\begin{array}{l}\text { Low functional capacity } \\
\text { History of stroke }\end{array}$ & Diabetes mellitus & Severe valvular disease \\
Uncontrolled hypertension & & \\
\hline
\end{tabular}


this with the research group and principal investigator (VE). These additional quality measures were taken to crosscheck our interpretations of the AC/AHA guidelines.

\section{Secondary outcome measurements}

Secondary outcome measurements were delay to surgery, perioperative complications and early and late mortality. We analyzed the complication rates in relation with delay to surgery. Mortality rates were recorded in-hospital and at 30-day, 1-year and 2-year interval.

\section{Statistical analysis}

All analyses were performed with SPSS 23 statistical software for windows (SPSS Inc., Chicago, Illinois, USA). $P<0.05$ was considered to be statistically significant. Data were presented as mean with standard deviation (SD) or as percentages when appropriate. In case of non-normal distributed, data were presented as median with interquartile range
(IR). One-way ANOVA were used to compare normally distributed and the Mann Whitney $U$ test for non-normally distributed continuous variables with Bonferroni correction for multiple testing. A Pearsons chi-square $\left(\chi^{2}\right)$ test was used to investigate whether distributions of categorical variables differed from one another. We used a Kaplan-Meier survival curve to investigate the mortality rates for each of the cardiac risk groups, comparing outcome using log rank analysis. A univariate logistic analysis of the postoperative complications was performed to identify risk factors early mortality. All important variables from univariate analysis for mortality were entered in a multivariate regression analysis.

\section{Results}

In the study period 166 consecutive patients were eligible for inclusion. Patient and operative characteristics are presented with the representative cardiac risk groups in Table 2. There were no significant differences in preoperative status
Table 2 Patient and operation characteristics

\begin{tabular}{|c|c|c|c|c|}
\hline \multirow[t]{2}{*}{ Variables } & \multicolumn{4}{|c|}{ ACC/AHA cardiac risk group } \\
\hline & Low $\%(n) n=108$ & $\begin{array}{l}\text { Intermedi- } \\
\text { ate } \%(n) \\
n=45\end{array}$ & High $\%(n) n=13$ & Total $\%(n) n=166$ \\
\hline Median age (years) & 85 (IR 11) & 83 (IR 11) & 84 (IR 6) & 84 (R 65-99) \\
\hline Female sex & $68 \%(73)$ & $67 \%(30)$ & $85 \%(11)$ & $69 \%(114)$ \\
\hline ASA (median) & 3 (IR 1) & 3 (IR 0) & 4 (IR 0) & 3 (R 1-4) \\
\hline Barthel index (median) & 18 (IR 7) & 17 (IR 7) & 13 (IR 11) & 17 (R 1-20) \\
\hline Palmer and Parker score (median) & 6 (IR 5) & 6 (IR 5) & 4 (IR 5) & 6 ( R 0-9) \\
\hline MET (median) & 4 (IR 3) & 4 (IR 3) & 2 (IR 3) & $4(\mathrm{R} 0-10)$ \\
\hline MMSE (median) & 25 (IR 12) & 25 (IR 12) & 17 (IR 15) & $21(\mathrm{R} 0-30)$ \\
\hline Mobility not impaired & $39 \%(40 / 102)$ & $40 \%(17 / 43)$ & $18 \%(2 / 11)$ & $38 \% 59 / 156$ \\
\hline Use of walking aids & $48 \%(49 / 102)$ & $33 \%(14 / 43)$ & $36 \%(4 / 11)$ & $43 \% 67 / 156$ \\
\hline Strongly impaired/indoors & $10 \%(10 / 102)$ & $23 \%(10 / 43)$ & $36 \%(4 / 11)$ & $15 \% 24 / 156$ \\
\hline Immobile - transfers & $3 \%(3 / 102)$ & $5 \%(2 / 43)$ & $9 \%(1 / 11)$ & $4 \% 6 / 156$ \\
\hline Intracapsular fractures & $47 \%(50 / 107)$ & $51 \%(23 / 45)$ & $62 \%(8 / 13)$ & $48 \%(80)$ \\
\hline Extracapsular fractures & $53 \%(57 / 107)$ & $49 \%(22 / 45)$ & $38 \%(5 / 13)$ & $51 \%(85)$ \\
\hline General anesthesia & $57 \%(56 / 99)$ & $60 \%(25 / 42)$ & $73 \%(8 / 11)$ & $54 \%(89)$ \\
\hline Spinal anesthesia & $43 \%(43 / 99)$ & $40 \%(17 / 42)$ & $27 \%(3 / 11)$ & $38 \%(63)$ \\
\hline Operation time (min., mean) & 69 (SD 28) & 70 (SD 27) & 85 (SD 25) & 71 (SD 28) \\
\hline Delay to surgery (h., median) & 23 (IR 20) & 25 (IR 17) & 31 (IR 46) & 27 (R 2-135) \\
\hline$>24 \mathrm{~h}$ & $44 \%(47 / 106)$ & $53 \%(23 / 43)$ & $62 \%(8 / 13)$ & $47 \%(78)$ \\
\hline$>48 \mathrm{~h}$ & $10 \%(10 / 106)$ & $5 \%(2 / 43)$ & $38 \%(5 / 13)^{* / * *}$ & $10 \%(17)$ \\
\hline Hospital stay (days, median) & 8 (IR 6) & 10 (IR 9) & 16 (IR 9) & 9 (R 2-59) \\
\hline
\end{tabular}

ASA American Society of Anesthesiologists score, range 1-6; Barthel Index score for functional capacity, range 0-20, Palmer and Parker score for mobility, range 0-9, MET metabolic equivalent of task score for physical activity, range $0->10, M M S E$ mini mental state examination score for measure cognitive impairment, range 0-30, IR interquartile range in case of non-normal distributed data, $R$ range of data, minimummaximum, $S D$ standard deviation, in case of normal distributed data

*Significant difference in compare with low risk group, $p<0.05$

**Significant difference in compare with intermediate risk group, $p<0.05$ 
concerning ASA score, the Barthel index for functional evaluation, Metabolic Equivalent of Task (MET) score for functional capacity, Mini Mental State Examination (MMSE) for cognitive impairment and the Palmer and Parker score for mobility.

In total $8 \%$ (13/166) of patients were predicted to have a high perioperative complication risk, 27\% (45/166) an intermediate risk and 65\% (108/166) a low risk. In $11(6.6 \%)$ patient's preoperative mobility scores could not be accurately determined at admittance due to cognitive impairment and unavailability of relatives to give correct information. These data were regarded as missing data, other available data of these patients were still used for analysis. There were no significant differences concerning operative characteristics between the cardiac risk groups (Table 2).

\section{Preoperative cardiac evaluation}

According to the guideline 93\% (100/108) in the low risk group, $76 \%$ (34/45) in the intermediate risk group and $85 \%$ (11/13) in the high risk group received correct preoperative cardiac screening (Table 3). Of all patients 13\% (21/166) did not receive the correct preoperative screening. The main reason for this was due to overscreening in $90 \%$ of the cases (19/21); 59\% (98/166) of the patients had a cardiovascular history, which did not necessarily imply active cardiac conditions. The chance to receive a cardiac consultation increased with the patient's perioperative cardiac risk group assignment, 9\%, 33\% and 100\% in the low, intermediate and high risk group, respectively. We found no significant differences in outcome in the overscreening group vs correctly screened patients.

\section{Delay to surgery}

The median delay to surgery was $23 \mathrm{~h}$ (IR 20), $23 \mathrm{~h}$ (IR 17) and $31 \mathrm{~h}$ (IR 46) for the low, intermediate and high risk group, respectively. The mean delay to surgery increased by $9.0 \mathrm{~h}$ (SD 25-44) when patients had a cardiac consultation $(p=0.06)$. High risk patients received significantly more preoperative cardiac consultations and had more often a delay to surgery of $>48 \mathrm{~h}(p<0.005$ in comparison with the low risk an intermediate risk group). Multivariate analysis showed that a cardiac consultation $(p=0.003)$ and overscreening $(p=0.02)$ were significant risk factors for increased delay to surgery, while age, sex, preoperative cardiac history and preoperative mobility were not influencing delay to surgery. In univariate analysis patients with a delay to surgery of $>48 \mathrm{~h}$ had significantly more respiratory complications $(p=0.04)$. In multivariate analysis an increased delay to surgery was an independent predictor for in-hospital mortality $(p=0.03)$ and 30-day mortality $(p=0.02)$ independent from cardiac risk category.

\section{Postoperative complications}

Postoperative complications are presented by cardiac risk group in Table 4. Respiratory and cardiovascular complications occurred significantly more often in the high risk group in comparison with the intermediate and low risk group $(p<0.02)$. This was related to a significantly higher risk for in-hospital death. Pulmonary complications (RR 37.95\% CI 9-156; $p<0.0001$ ), and cardiovascular complications (RR 9.95\% CI 3-24; $p<0.0001$ ) were significant risk factors for in-hospital mortality. In a multivariate analysis an increased delay to surgery was an independent risk factor for respiratory complications $(p=0.009)$. Furthermore, a multivariate regression analysis for cardiovascular complications showed that a cardiac history was a significant risk factor, but not age, sex or delay to surgery $(p=0.001)$.

\section{Mortality}

The mortality rates by cardiac risk group are summarized in Table 5. A Kaplan-Meier curve for survival was made with a follow up of 24 months in Fig. 1 (lost to follow-up
Table 3 Preoperative cardiac evaluations

\begin{tabular}{lllll}
\hline \multicolumn{5}{l}{ ACC/AHA cardiac risk group } \\
\cline { 2 - 5 } & Low \%(n) $n=108$ & $\begin{array}{l}\text { Intermediate } \\
\%(n) n=45\end{array}$ & High $\%(n) n=13$ & Total \%(n) $n=166$ \\
\hline Cardiac history & $28 \%(30)$ & $80 \%(36)^{*}$ & $92 \%(12)^{* / * *}$ & $47 \%(78)$ \\
Cardiac consultation & $9 \%(10)$ & $33 \%(15)^{*}$ & $100 \%(13)^{* / * *}$ & $23 \%(38)$ \\
$\begin{array}{l}\text { Cardiac screening in accord- } \\
\text { ance with ACC/AHA }\end{array}$ & $93 \%(100)$ & $76 \%(34)^{*}$ & $85 \%(11)^{*}$ & $87 \%(145)$ \\
guidelines & & & & \\
Overscreening & $7 \%(8)$ & $20 \%(9)$ & $15 \%(2)$ & $11 \%(19)$ \\
Underscreening & 0 & $4 \%(2)$ & 0 & $12 \%(2)$ \\
\hline
\end{tabular}

*Significant difference in compare with low risk group, $p<0.05$

$* *$ Significant difference in compare with intermediate risk group, $p<0.05$ 
Table 4 Complications

\begin{tabular}{|c|c|c|c|c|}
\hline \multirow{2}{*}{ Complications } & \multicolumn{4}{|c|}{ ACC/AHA cardiac risk group } \\
\hline & Low $\%(n) n=108$ & $\begin{array}{l}\text { Intermediate } \\
\%(n) n=45\end{array}$ & $\operatorname{High} \%(n) n=13$ & Total $\%(n) n=166$ \\
\hline Number of complications & $1($ IR 1$)$ & 1 (IR 1) & 2 (IR 2) & 1 ( R 0-7) \\
\hline Delirium & $25 \%(27)$ & $20 \%(9)$ & $31 \%(4)$ & $24 \%(40)$ \\
\hline Wound infection & $6 \%(6)$ & $13 \%(6)$ & 0 & $7 \%(12)$ \\
\hline Blood transfusion & $43 \%(46)$ & $38 \%(17)$ & $61 \%(8)$ & $43 \%(71)$ \\
\hline Urinary tract Infection & $17 \%(18)$ & $16 \%(7)$ & 0 & $15 \%(25)$ \\
\hline Pressure sores & $4 \%(4)$ & $9 \%(4)$ & 0 & $5 \%(8)$ \\
\hline Respiratory & $11 \%(12)$ & $11 \%(5)$ & $46 \%(6)^{* / * *}$ & $14 \%(23)$ \\
\hline Pneumonia & $8 \%(9)$ & $9 \%(4)$ & $31 \%(4)^{*}$ & $10 \%(17)$ \\
\hline Pulmonary embolism & 0 & 0 & 0 & 0 \\
\hline Respiratory failure & $5 \%(5)$ & $7 \%(28)$ & $23 \%(28)^{*}$ & $7 \%(11)$ \\
\hline Gastrointestinal tract bleeding & $4 \%(4)$ & $2 \%(1)$ & 0 & $3 \%(5)$ \\
\hline Gastrointestinal $^{\mathrm{a}}$ & $2 \%(2)$ & $2 \%(1)$ & 0 & $2 \%(28)$ \\
\hline Cardiovascular & $6 \%(7)$ & $31 \%(14)^{*}$ & $62 \%(8)^{* / * *}$ & $17 \%(29)$ \\
\hline Stroke & $1 \%(1)$ & $2 \%(1)$ & 0 & $1 \%(2)$ \\
\hline Rhythm disorders & $2 \%(2)$ & $13 \%(6)^{*}$ & $38 \%(5)^{* / * *}$ & $8 \%(13)$ \\
\hline AMI & $2 \%(2)$ & $9 \%(4)$ & $15 \%(2)$ & $5 \%(8)$ \\
\hline Cardiac failure & $5 \%(5)$ & $11 \%(5)$ & $38 \%(5)^{* / * *}$ & $9 \%(15)$ \\
\hline Neurological & $1 \%(1)$ & $2 \%(1)$ & 0 & $1 \%(2)$ \\
\hline Implant failure $^{b}$ & $7 \%(8)$ & $2 \%(1)$ & $8 \%(1)$ & $6 \%(10)$ \\
\hline In-hospital mortality & $6 \%(6 / 108)$ & $9 \%(4 / 45)$ & $31 \%(4 / 13)^{* / * *}$ & $8 \%(14 / 166)$ \\
\hline
\end{tabular}

*Significant difference in compare with low risk group, $p<0.05$

**Significant difference in compare with intermediate risk group, $p<0.05$

${ }^{\text {a}}$ Postoperative ileus, extensive diarrhea, ischemia

${ }^{b}$ Re-operation, luxation or deep infection of the arthroplasty or fracture fixation.

Respiratory complications consist of pneumonia, pulmonary embolism and respiratory failure together. Cardiovascular complications consist of stroke, rhythm disorders, acute myocardial infarction (AMI) and cardiac failure. IR interquartile range in case of non-normal distributed data, $R$ range of data, minimummaximum

Table 5 Mortality rates

\begin{tabular}{lllll}
\hline Mortality & \multicolumn{4}{l}{ ACC/AHA cardiac risk group } \\
\cline { 2 - 5 } & Low $\%(n)$ & Intermediate $\%(n)$ & High $\%(n)$ & Total \% (n) \\
\hline In-hospital & $6 \%(6 / 108)$ & $9 \%(4 / 45)$ & $31 \%(4 / 13)^{* / * *}$ & $8 \%(14 / 166)$ \\
30-day & $9 \%(9 / 102)$ & $16 \%(7 / 43)$ & $41 \%(5 / 12)^{*}$ & $13 \%(21 / 157)$ \\
1-year & $25 \%(25 / 102)$ & $37 \%(16 / 43)$ & $58 \%(7 / 12)^{*}$ & $31 \%(48 / 157)$ \\
2-year & $30 \%(31 / 102)$ & $44 \%(19 / 43)$ & $75 \%(9 / 12)^{*}$ & $38 \%(59 / 157)$ \\
\hline
\end{tabular}

*Significant difference in compare with low risk group, $p<0.05$

**Significant difference in compare with intermediate risk group, $p<0.05$

after discharge $n=9$ ). The mortality rates increased with the cardiac risk category. This led to significantly higher mortality in high risk patients for the in-hospital, 30-day, 1 -year and 2-year mortality in comparison with low risk patients. High risk patients had in comparison with low risk patients a relative risk ratio (RR) of 6 (95\% CI 2-17) for in-hospital mortality, RR 5 (95\% CI 2-12) for 30-day mortality, RR 2 (95\% CI 1.3-4) for 1-year mortality and
RR 2 (95\% CI 2-4) for 2-year mortality. In-hospital mortality was due to cardiovascular complications in $50 \%$ of cases, followed by respiratory failure in $36 \%$ of cases and in $14 \%$ because of other reasons.

Mortality rates in relation with a prior cardiac history are presented in Table 6 . These results show that a previous cardiac history is related with $>3.5$ fold higher early 


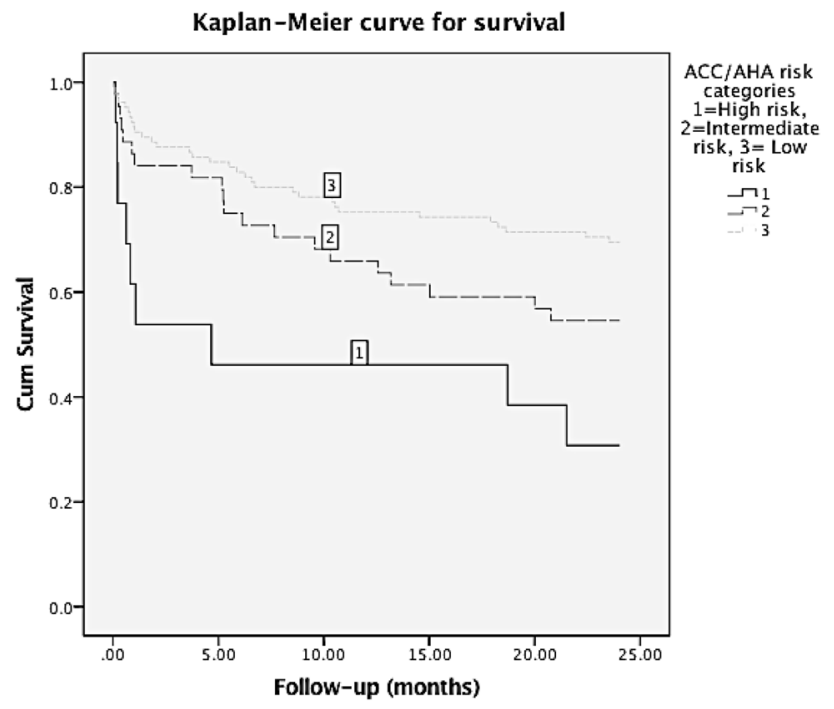

Fig. 1 Survival curve

Table 6 Mortality rates in relation to prior cardiac history

\begin{tabular}{|c|c|c|c|}
\hline Mortality & No cardiac history $\%(n)$ & Cardiac history $\%(n)$ & $p$ \\
\hline In-hospital & $2 \%(2 / 88)$ & $15 \%(12 / 78)$ & 0.002 \\
\hline 30-day & $6 \%(5 / 83)$ & $22 \%(16 / 74)$ & 0.004 \\
\hline 1-year & $24 \%(20 / 83)$ & $38 \%(28 / 74)$ & $<0.05$ \\
\hline 2-year & $28 \%(23 / 83)$ & $49 \%(36 / 74)$ & 0.005 \\
\hline
\end{tabular}

Significant difference for $p<0.05$

mortality, or $>1.7$ fold higher late mortality in comparison with no previous cardiac history.

A Cox multiple regression analysis for mortality for the complete follow-up period of 24 months showed that high age was the only significant risk factor. With linear regression analysis we studied potential risk factors for early and late mortality (see Table 7). A cardiac history and increased delay to surgery were predictors for early mortality (in-hospital and 30-day). A high age and a cardiac history were found risk factors for late mortality.

\section{Discussion}

In this prospective cohort study $87 \%$ of patients received preoperative cardiac screening in adherence to the ACC/ AHA guideline. The most frequent reason for incorrect preoperative cardiac screening was overscreening (>90\%). High risk patients received significantly more preoperative cardiac consultations and experienced more often a delay to surgery of $>48 \mathrm{~h}$. Multivariate analysis showed that a cardiac consultation and overscreening are significant predictors for increased delay to surgery, while age, sex, a previous cardiac history and preoperative mobility were not. Early mortality (in-hospital and 30-day) was determined by a previous cardiac history and increased delay to surgery. High age and a previous cardiac history were predictors for late mortality.

Preoperative cardiac screening for hip fracture patients has been subject to debate between surgeons and anesthesiologists. Therefore, the ACC/AHA provides guidelines for preoperative cardiac screening to minimize the risk for perioperative cardiac complications and preventing overuse of medical resources. High risk patients might benefit from delaying hip fracture surgery to optimize or stabilizing the cardiac comorbidities. Nevertheless, delaying surgery with a cardiac consultation that is not recommended or contributing could lead to worse outcome. Cardiac consultations increase delay to surgery, which is confirmed by several other studies $[7,20]$. However, in this study, no significant differences in postoperative complications in the overscreening group vs correctly screened patients were found, which may be due to a small sample size. Another important issue is the content of cardiac consultations. Consultations are frequently limited to a statement of the increased surgical risk and make general recommendations concerning fluid balance, maintaining hemoglobin levels and continuing beta-blocker medication.

Stitgen et al. showed that $85 \%$ of patients were correctly screened according to the ACC/AHA guideline [6]. In our previous retrospective study on this matter $(n=388)$, we demonstrated $72 \%$ correctly screened patients [7] vs $87 \%$ in this study. The number of cardiac consultations has dropped to $23 \%$ in this study vs. $38 \%$ in our previous study.
Table 7 Linear regression analysis for mortality

\begin{tabular}{llllc}
\hline Variables & $\begin{array}{l}\text { In-hospital mortal- } \\
\text { ity }(p)\end{array}$ & $\begin{array}{l}\text { 30-day mortal- } \\
\text { ity }(p)\end{array}$ & $\begin{array}{l}\text { 1-year mortal- } \\
\text { ity }(p)\end{array}$ & 2-year mortality $(p)$ \\
\hline Sex & 0.2 & 0.1 & 0.2 & 0.6 \\
Age & 0.7 & 0.7 & 0.001 & $<0.0001$ \\
Delay to surgery & 0.03 & 0.02 & 0.1 & 0.2 \\
Cardiac history & 0.005 & 0.008 & 0.2 & 0.04 \\
\hline
\end{tabular}

Significant difference for $p<0.05$ 
In addition, we found a marked decline in patients who were overscreened, $13 \%$ vs. $27 \%$ in our previous study. The most profound findings were in the intermediate risk group, where $24 \%$ of patients were not screened in accordance with the guidelines vs $54 \%$ in our previous study. The reason for incorrect preoperative cardiac screening in both our studies remained in $>90 \%$ of cases due to overscreening. We consider increased awareness of surgeons as well as anesthesiologists of the ACC/AHA guidelines and a reduced incidence of instant cardiac consultations requested by the physician at the emergency department for cardiac clearance are contributing to these findings. Sometimes the goal of preoperative screening seems to be to strive for 'cardiac clearance', some sort of cardiac approval that must be obtained before operation.

According to ACC/AHA guideline, patients who require non-invasive cardiac testing are those with active high risk cardiac conditions and those with intermediate risk clinical predictors combined with poor functional capacity. Whether a consultation is justified for patients in the intermediate risk group is decided by their functional capacity, measured by metabolic equivalent of task (METs), which is rather arbitrary. Currently, there exist no other clinical screening tools to identify those patients who need a cardiac consultation prior to hip fracture surgery.

It has been suggested to routinely perform an echocardiography in elderly patients with hip fractures [21]. Some authors have reported a benefit of routine echocardiography on mortality after hip fracture surgery [22], where others have not $[23,24]$. Screening all hip fracture patients with transthoracic echocardiography (TTE) identified in $8 \%$ of patients significant aortic stenosis. Conversely severe aortic stenosis is no contraindication for surgery and does not influence early mortality [25, 26]. Another study found that preoperative TTE leads to an increased delay to surgery [9]. Delay to surgery is associated with worse outcome after hip fracture surgery [5, 23, 27-30]. Furthermore, TTE screening has cost implications, as this needs to be a continuously available service. There are no recommendations available from randomized controlled trials on the use of TTE screening in a hip fracture population. One retrospective matchedcontrol study showed lower postoperative and 1-year mortality rates after focused TTE screening in a hip fracture population [22]. Unclear is whether these patients were only intermediate risk patients or also high risk patients and what their functional capacity was. Screening patients with a high chance of pathology is more logical than screening all hip fracture patients, therefore in the low risk group is TTE screening probably not useful and second not indicated by the ACC/AHA guideline.

A preoperative cardiac consultation rarely affects surgical management, but may influence anesthesiologic management, especially cardiovascular and fluid management after non-invasive testing with TTE in high risk or intermediate risk patients with low METs. The ACC/AHA guideline recommendation is level B evidence and is merely based on dobutamine stress echocardiography which is rarely used in the hip fracture population. Instead, bedside echocardiography without stress testing is performed to report on global cardiac and valvular function and volume status. The guideline states that non-invasive cardiac testing is reasonable for intermediate risk patients with $<4$ METs if it will change patient management. As a result of this, TTE is probably most frequently overused in the intermediate risk group. Other indications for preoperative TTE are new developed dyspnoea without known aetiology or decompensated heart failure [31]. A study showed that TTE in accordance with the ACC/AHA guideline in only $14 \%$ of patients revealed disease with the potential to modify anesthesia or medical management [32]. If non-invasive cardiac testing like TTE prior to surgery is indicated, this should be performed without delay to surgery.

Not every form of anesthesia is equally suitable for every geriatric patient [33]. To improve outcome of high risk patients, some intraoperative strategies were studied in the literature. Continuous spinal anesthesia (CSA), with (minimally invasive) hemodynamic monitoring is suggested as alternative anesthesia in the case of severe aortic stenosis with minimal hemodynamic changes intraoperatively in hip fracture patients [34, 35]. CSA compared with combined spinal epidural anesthesia (CSE) showed better sensory blockade level and lower hemodynamic changes in 240 patients following major orthopaedic surgery [36]. According to a Cochrane systematic review, other advanced hemodynamic monitoring strategies, such as esophageal Doppler monitoring, goal-directed hemodynamic treatment (with LiDCO monitor) or Swan Ganz pulmonary-artery catheter in comparison with standard care and conventional fluid management did not show improvement on postoperative outcome after hip fracture surgery [37].

Respiratory and cardiovascular complications occurred significantly more often in the high risk group in comparison with the intermediate and low risk group and increased the risk for in-hospital death fivefold to a 30-day mortality rate of $31 \%$. Another study found that pneumonia and heart failure after hip fracture surgery lead to a mortality rate of $43 \%$ and $65 \%$, respectively [38]. Three or more co-morbidities, respiratory disease and malignancy were preoperative variables that were significantly related to increased 30-day mortality. In a multivariate regression analysis, we showed that a previous cardiac history was a predictor for early and late mortality. The increased early mortality in the cardiac history group could be explained by postoperative respiratory and cardiovascular complications and the increased late mortality could be explained by the effect of comorbidity on the long-term. We did not examine whether patients with 
a cardiac history had equal recovery chances compared to patients without a cardiac history.

Mortality after hip fracture remains high and extremely high for high risk patients. Hip fractures are associated with an in-hospital mortality rate of $7-14 \%$, reaching up to $36 \%$ within 1 year of surgery [7, 39-43]. Over the past 3 decades, mortality rates after hip fracture surgery hardly changed. One year mortality for intertrochanteric fractures remained about $23 \%$ after 1999 [44]. Although a steady decrease was found in the UK, 11\% 30-day mortality in 2003 decreased to $8 \%$ in 2013 [45]. A combined number of improvements of care, including the implementation of fast-track care pathways, input from orthogeriatricians, quick patient medical optimization, early surgery and advanced rehabilitation protocols have contributed to this $[33,45]$.

In conclusion, preoperative cardiac screening in adherence to the ACC/AHA guideline is associated with a diminished use of preoperative resources. Overscreening leads to greater delay to surgery, which poses a risk for perioperative complications and early mortality.

\section{Compliance with ethical standards}

Conflict of interest All of the authors declare that there is no conflict of interest.

Open Access This article is distributed under the terms of the Creative Commons Attribution 4.0 International License (http://creativecommons.org/licenses/by/4.0/), which permits unrestricted use, distribution, and reproduction in any medium, provided you give appropriate credit to the original author(s) and the source, provide a link to the Creative Commons license, and indicate if changes were made.

\section{References}

1. Sathiyakumar V, Avilucea FR, Whiting PS, Jahangir AA, Mir HR, Obremskey WT, Sethi MK (2016) Risk factors for adverse cardiac events in hip fracture patients: an analysis of NSQIP data. Int Orthop 40(3):439-445. https://doi.org/10.1007/s0026 4-015-2832-5

2. Fleisher LA, Beckman JA, Brown KA, Calkins H, Chaikof E, Fleischmann KE, Freeman WK, Froehlich JB, Kasper EK, Kersten JR, Riegel B, Robb JF, Smith SC Jr, Jacobs AK, Adams CD, Anderson JL, Antman EM, Buller CE, Creager MA, Ettinger SM, Faxon DP, Fuster V, Halperin JL, Hiratzka LF, Hunt SA, Lytle BW, Nishimura R, Ornato JP, Page RL, Tarkington LG, Yancy CW (2007) ACC/AHA 2007 guidelines on perioperative cardiovascular evaluation and care for noncardiac surgery: a report of the American College of Cardiology/American Heart Association Task Force on Practice Guidelines (Writing Committee to Revise the 2002 Guidelines on Perioperative Cardiovascular Evaluation for Noncardiac Surgery): developed in collaboration with the American Society of Echocardiography, American Society of Nuclear Cardiology, Heart Rhythm Society, Society of Cardiovascular Anesthesiologists, Society for Cardiovascular Angiography and Interventions, Society for Vascular Medicine and Biology, and
Society for Vascular Surgery. Circulation 116(17):e418-499. https ://doi.org/10.1161/CIRCULATIONAHA.107.185699

3. Shiga T, Wajima Z, Ohe Y (2008) Is operative delay associated with increased mortality of hip fracture patients? Systematic review, meta-analysis, and meta-regression. Can J Anaesth 55(3):146-154. https://doi.org/10.1007/BF03016088

4. Khan SK, Kalra S, Khanna A, Thiruvengada MM, Parker MJ (2009) Timing of surgery for hip fractures: a systematic review of 52 published studies involving 291,413 patients. Injury 40(7):692-697. https://doi.org/10.1016/j.injury.2009.01.010

5. Simunovic N, Devereaux PJ, Sprague S, Guyatt GH, Schemitsch E, Debeer J, Bhandari M (2010) Effect of early surgery after hip fracture on mortality and complications: systematic review and meta-analysis. CMAJ 182(15):1609-1616. https://doi. org/10.1503/cmaj.092220

6. Stitgen A, Poludnianyk K, Dulaney-Cripe E, Markert R, Prayson M (2015) Adherence to preoperative cardiac clearance guidelines in hip fracture patients. J Orthop Trauma 29(11):500-503. https://doi.org/10.1097/BOT.0000000000000381

7. Smeets SJ, Poeze M, Verbruggen JP (2012) Preoperative cardiac evaluation of geriatric patients with hip fracture. Injury 43(12):2146-2151. https://doi.org/10.1016/j.injury.2012.08.007

8. Jettoo P, Kakwani R, Junejo S, Talkhani I, Dixon P (2011) Pre-operative echocardiogram in hip fracture patients with cardiac murmur-an audit. J Orthop Surg Res 6:49. https://doi. org/10.1186/1749-799X-6-49

9. O'HEireamhoin S, Beyer T, Ahmed M, Mulhall KJ (2011) The role of preoperative cardiac investigation in emergency hip surgery. J Trauma 71(5):1345-1347. https://doi.org/10.1097/ TA.0b013e318224cfa3

10. Chong CP, van Gaal WJ, Savige J, Lim WK (2011) Cardiac injury and troponin testing after orthopaedic surgery. Injury 42(9):855-863

11. Spurrier E, Wordsworth D, Martin S, Norris R, Parker MJ (2011) Troponin T in hip fracture patients: prognostic significance for mortality at one year. Hip Int 21(6):757-761. https:// doi.org/10.5301/HIP.2011.8840

12. Nettleman MD, Alsip J, Schrader M, Schulte M (1996) Predictors of mortality after acute hip fracture. J Gen Intern Med 11(12):765-767

13. Perez JV, Warwick DJ, Case CP, Bannister GC (1995) Death after proximal femoral fracture-an autopsy study. Injury 26(4):237-240

14. Nederlandse Vereniging van Heelkunde NVvH, Nederlandse Orthopaedische Vereniging NOV (2016) Proximale femurfracturen (guideline). https://richtlijnendatabase.nl

15. Dripps RD (1963) New classification of physical status. Anesthesioly 24 (111)

16. Mahoney FI, Barthel DW (1965) Functional evaluation: the Barthel index. Md State Med J 14:61-65

17. Jette M, Sidney K, Blumchen G (1990) Metabolic equivalents (METS) in exercise testing, exercise prescription, and evaluation of functional capacity. Clin Cardiol 13(8):555-565

18. Folstein MF, Robins LN, Helzer JE (1983) The mini-mental state examination. Arch Gen Psychiatry 40(7):812

19. Parker MJ, Palmer CR (1993) A new mobility score for predicting mortality after hip fracture. J Bone Jt Surg Br 75(5):797-798

20. Mutlu H, Bilgili F, Mutlu S, Karaman O, Cakal B, Ozkaya U (2016) The effects of preoperative non-invasive cardiac tests on delay to surgery and subsequent mortality in elderly patients with hip fracture. J Back Musculoskelet Rehabil 29(1):49-54. https:// doi.org/10.3233/BMR-150595

21. Heyburn G, McBrien ME (2012) Pre-operative echocardiography for hip fractures: time to make it a standard of care. Anaesthesia 67(11):1189-1193. https://doi.org/10.111 1/j.1365-2044.2012.07330.x 
22. Canty DJ, Royse CF, Kilpatrick D, Bowyer A, Royse AG (2012) The impact on cardiac diagnosis and mortality of focused transthoracic echocardiography in hip fracture surgery patients with increased risk of cardiac disease: a retrospective cohort study. Anaesthesia 67(11):1202-1209. https://doi.org/10.111 1/j.1365-2044.2012.07300.x

23. Marcantonio A, Steen B, Kain M, Bramlett KJ, Tilzey JF (2013) Iorio R (2015) The clinical and economic impact of preoperative transthoracic echocardiography in elderly patients with hip fractures. Bull Hosp Jt Dis 73(4):239-242

24. Luttrell K, Nana A (2015) Effect of preoperative transthoracic echocardiogram on mortality and surgical timing in elderly adults with hip fracture. J Am Geriatr Soc 63(12):2505-2509. https://doi. org/10.1111/jgs. 13840

25. Leibowitz D, Rivkin G, Schiffman J, Rott D, Weiss AT, Mattan Y, Kandel L (2009) Effect of severe aortic stenosis on the outcome in elderly patients undergoing repair of hip fracture. Gerontology 55(3):303-306. https://doi.org/10.1159/000209245

26. McBrien ME, Heyburn G, Stevenson M, McDonald S, Johnston NJ, Elliott JR, Beringer TR (2009) Previously undiagnosed aortic stenosis revealed by auscultation in the hip fracture population-echocardiographic findings, management and outcome. Anaesthesia 64(8):863-870. https://doi.org/10.111 $1 / \mathrm{j} .1365-2044.2009 .05960 . \mathrm{x}$

27. Bretherton CP, Parker MJ (2015) Early surgery for patients with a fracture of the hip decreases 30-day mortality. Bone Jt J 97-B(1):104-108. https://doi. org/10.1302/0301-620X.97B1.35041

28. Carretta E, Bochicchio V, Rucci P, Fabbri G, Laus M, Fantini MP (2011) Hip fracture: effectiveness of early surgery to prevent 30-day mortality. Int Orthop 35(3):419-424. https://doi. org/10.1007/s00264-010-1004-x

29. Uzoigwe CE, Burnand HG, Cheesman CL, Aghedo DO, Faizi M, Middleton RG (2013) Early and ultra-early surgery in hip fracture patients improves survival. Injury 44(6):726-729. https://doi. org/10.1016/j.injury.2012.08.025

30. Lewis PM, Waddell JP (2016) When is the ideal time to operate on a patient with a fracture of the hip?: a review of the available literature. Bone Jt J 98-B(12):1573-1581. https://doi. org/10.1302/0301-620X.98B12.BJJ-2016-0362.R2

31. Fleisher LA, Beckman JA, Brown KA, Calkins H, Chaikof EL, Fleischmann KE, Freeman WK, Froehlich JB, Kasper EK, Kersten JR, Riegel B, Robb JF, American College of C, American Heart Association Task Force on Practice G, Writing Committee to Update the Guidelines on Perioperative Cardiovascular Evaluation for Noncardiac S, American Society of E, American Society of Nuclear C, Heart Rhythm S, Society of Cardiovascular A, Society for Cardiovascular A, Interventions, Society for Vascular M, Biology (2007) ACC/AHA 2006 guideline update on perioperative cardiovascular evaluation for noncardiac surgery: focused update on perioperative beta-blocker therapy - a report of the American College of Cardiology/American Heart Association Task Force on Practice Guidelines (Writing Committee to Update the 2002 Guidelines on Perioperative Cardiovascular Evaluation for Noncardiac Surgery). Anesth Analg 104(1):15-26. https://doi. org/10.1213/01.ane.0000243335.31748.22

32. Adair C, Swart E, Seymour R, Patt J, Karunakar MA (2017) Clinical Practice Guidelines Decrease Unnecessary Echocardiograms
Before Hip Fracture Surgery. J Bone Joint Surg Am 99(8):676680. https://doi.org/10.2106/JBJS.16.01108

33. Luger TJ, Luger MF (2016) Anesthesiological care in orthogeriatric co-management Perioperative treatment of geriatric trauma patients. Z Gerontol Geriatr 49(3):237-255. https://doi. org/10.1007/s00391-016-1057-6

34. Lopez MM, Guasch E, Schiraldi R, Maggi G, Alonso E, Gilsanz F (2016) Continuous spinal anaesthesia with minimally invasive haemodynamic monitoring for surgical hip repair in two patients with severe aortic stenosis. Braz J Anesthesiol 66(1):82-85. https ://doi.org/10.1016/j.bjane.2013.03.010

35. Dohler S, Klippel A, Richter S (1999) Continuous spinal anesthesia in very elderly patients with high anesthesia risk in traumatologic-orthopedic and general surgery interventions. Anaesthesiol Reanim 24(6):157-163

36. Imbelloni LE, Gouveia MA, Cordeiro JA (2009) Continuous spinal anesthesia versus combined spinal epidural block for major orthopedic surgery: prospective randomized study. Sao Paulo Med J 127(1):7-11

37. Lewis SR, Butler AR, Brammar A, Nicholson A, Smith AF (2016) Perioperative fluid volume optimization following proximal femoral fracture. Cochrane Database Syst Rev 3:CD003004. https://doi. org/10.1002/14651858.CD003004.pub4

38. Roche JJ, Wenn RT, Sahota O, Moran CG (2005) Effect of comorbidities and postoperative complications on mortality after hip fracture in elderly people: prospective observational cohort study. BMJ 331(7529):1374. https://doi.org/10.1136/bmj.38643.66384 3.55

39. Murphy DK, Randell T, Brennan KL, Probe RA, Brennan ML (2013) Treatment and displacement affect the reoperation rate for femoral neck fracture. Clin Orthop Relat Res 471(8):2691-2702. https://doi.org/10.1007/s11999-013-3020-9

40. Schemitsch E, Bhandari M (2009) Femoral neck fractures: controversies and evidence. J Orthop Trauma 23(6):385. https://doi. org/10.1097/BOT.0b013e3181acc51f

41. Simunovic N, Devereaux PJ, Bhandari M (2011) Surgery for hip fractures: Does surgical delay affect outcomes? Indian J Orthop 45(1):27-32. https://doi.org/10.4103/0019-5413.73660

42. Bottle A, Aylin P (2006) Mortality associated with delay in operation after hip fracture: observational study. BMJ 332(7547):947951. https://doi.org/10.1136/bmj.38790.468519.55

43. Weller I, Wai EK, Jaglal S, Kreder HJ (2005) The effect of hospital type and surgical delay on mortality after surgery for hip fracture. J Bone Jt Surg Br 87(3):361-366

44. Mundi S, Pindiprolu B, Simunovic N, Bhandari M (2014) Similar mortality rates in hip fracture patients over the past 31 years. Acta Orthop 85(1):54-59. https://doi.org/10.3109/17453 674.2013.878831

45. Giannoulis D, Calori GM, Giannoudis PV (2016) Thirty-day mortality after hip fractures: has anything changed? Eur J Orthop Surg Traumatol 26(4):365-370. https://doi.org/10.1007/s0059 0-016-1744-4

Publisher's Note Springer Nature remains neutral with regard to jurisdictional claims in published maps and institutional affiliations. 